\title{
Superior cerebellar hyperintense sign on FLAIR-weighted magnetic resonance imaging in paraneoplastic cerebellar degeneration
}

Sinal hipertenso do vérmis cerebelar superior na sequência FLAIR em um paciente com degeneração cerebelar paraneoplásica

Marcelo de Melo Aragão, José Luiz Pedroso, Marcus Vinicius Cristino Albuquerque, Livia Almeida Dutra, Orlando Graziani Povoas Barsottini

A 59 year-old woman presented with 15 days history of progressive gait instability and slurred speech. She had recurrence of breast cancer diagnosed five years before. Neurological examination showed dysarthria and ataxia. Brain magnetic resonance imaging (MRI) presented hyperintense sign in the superior cerebellar vermis and upper cerebellar hemispheres, without atrophy (Figure). Cerebrospinal fluid (CSF) revealed lymphocytic pleocytosis. Cerebellar degeneration is one of the most common neurological paraneoplastic syndromes. The most frequently associated tumors are: breast, ovary and lung cancer, and also lymphoma ${ }^{1}$. Early brain MRI is frequently normal or shows a diffuse enlargement of cerebellar hemispheres; rarely, there are signal changes in the cerebellar cortex ${ }^{2}$. After a few months, atrophy of the brainstem and cerebellum may appear.

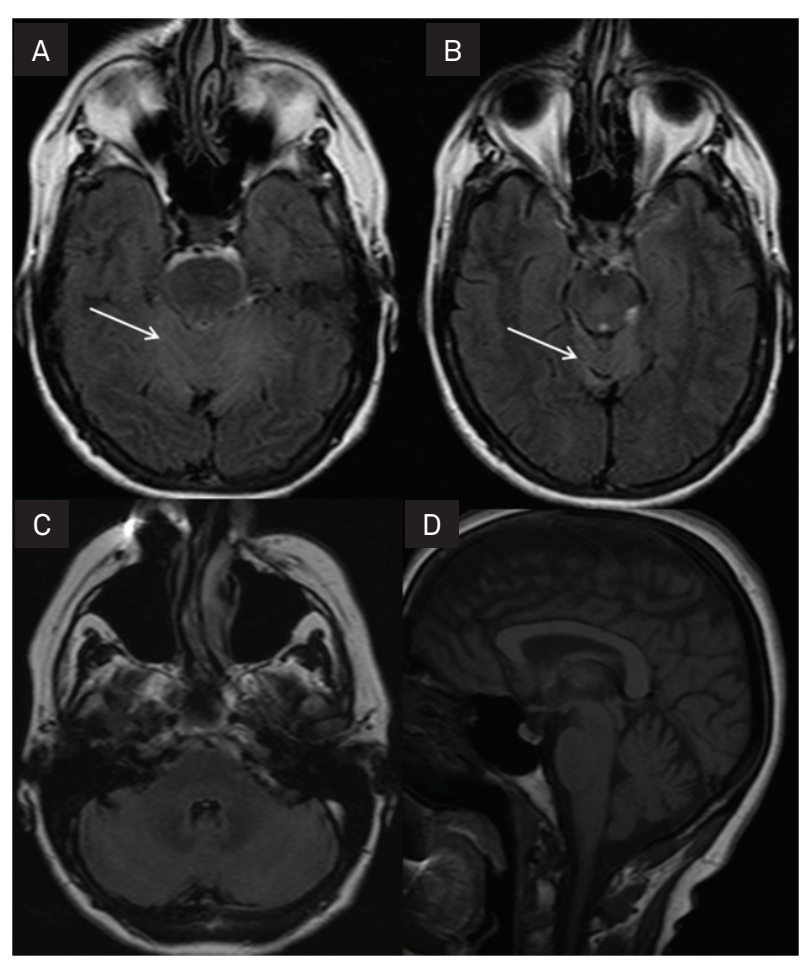

Figure. Axial FLAIR-weighted brain magnetic resonance imaging (MRI) disclosed hyperintense sign in the superior cerebellar vermis and upper cerebellar hemispheres ( $A$ and B); axial FLAIR and sagittal T1-weighted brain MRI shows no cerebellar atrophy (C and D).
1. Dalmau J, Rosenfeld MR. Paraneoplastic syndromes of the CNS. Lancet Neurol 2008;7:327-340. de Andrés C, Esquivel A, de Villoria JG, Graus F, Sánchez-Ramón S. Unusual magnetic imaging and cerebrospinal fluid findings in paraneoplastic cerebellar degeneration: a sequential study. J Neurol Neurosurg Psychiatry 2006;77:562-568.

Department of Neurology, Ataxia Unit, Universidade Federal de São Paulo (UNIFESP), São Paulo SP, Brazil.

Correspondence: José Luiz Pedroso; Rua Botucatu 740; 04023-900 São Paulo SP - Brasil; E-mail: zeluizpedroso@yahoo.com.br

Conflict of interest: There is no conflict of interest to declare.

Received 05 May 2012; Received in final form 03 September 2012; Accepted 10 September 2012 